\title{
Editorial
}

\section{Novos ventos}

Em nome da nova diretoria da revista Psicologia: Teoria e Pesquisa, gostaria de iniciar esta manifestação com o reconhecimento do notável trabalho desenvolvido pela diretoria cujo mandato há pouco se encerrou. Graças à incansável dedicação e ao esmero exibido em todas as atividades que desenvolveu, aquela equipe prestou inestimável contribuição à manutenção do alto padrão de qualidade científica de nossa publicação. Merecem destaque, entre as muitas conquistas obtidas, a implementação da periodicidade trimestral da revista e sua classificação como periódico A2 pela CAPES/Qualis.

Cabe à nova diretoria a imensa responsabilidade de manter os patamares de excelência já alcançados e de vencer desafios que ainda persistem, dentre os quais a reativação da plataforma SEER de tramitação eletrônica surge como o mais urgente. Por motivos técnicos, a migração da tramitação "manual" para a eletrônica teve que ser interrompida. Graças, porém, aos esforços da administração anterior, a reativação do processo ocorrerá em breve e sem grandes transtornos. Superado esse primeiro obstáculo, espera-se que o procedimento de tramitação editorial dos manuscritos submetidos ocorra de modo mais eficiente, com a conseqüente redução do tempo despendido nesse mister.

Este é o quarto e último número do volume 24, correspondente ao exercício de 2008. No total, foram publicados 61 artigos, duas resenhas e uma notícia, elaborados por autores nacionais de diversas universidades e regiões geográficas e por autores internacionais. Com isso, foi possível oferecer uma visão geral da produção teórico-metodológica e técnica da Psicologia atual.

Neste exemplar, os leitores terão a oportunidade de apreciar trabalhos realizados em vários ramos de nossa disciplina.

Na área de Psicologia do Desenvolvimento, quatro artigos lidam com questões relacionadas à infância e/ou adolescência. Susana Custódio e Orlanda Cruz avaliam a relação entre a representação mental de crianças acerca dos pais, enquanto figuras afetivas e disciplinares, e a competência social dessas crianças. Luciene Stivanin, Claudia Ines Scheuer e Francisco Baptista Assumpção Jr. investigam as características comportamentais de crianças com desenvolvimento típico de leitura, a partir da perspectiva de pais e professores. O papel das práticas culturais, da constituição do self e do desenvolvimento da autonomia na promoção da participação infantil em processos decisórios coletivos é discutido por Sergio Fernandes Senna Pires e Ângela Uchoa Branco. Por sua vez, Liana Gama do Vale e Heloisa Moulin de Alencar analisam o lugar da generosidade, em oposição à satisfação de interesses próprios, no universo moral de crianças e adolescentes.

Danilo Silva Guimarães e Lívia Mathias Simão ilustram alguns aspectos do processo de negociação intersubjetiva de significados em sessões de Jogos de Interpretação de Papéis, durante as quais adultos jovens buscavam o compartilhamento de experiências com o outro. Com relação aos idosos, Danielle Macedo, Carolina Vilela Oliveira, Isolda de Araújo Günther, Susana Martins Alves e Thaís Santos Nóbrega averiguam a influência do afeto relacionado a interações com o ambiente e do estado emocional (alegre ou triste) do indivíduo sobre a configuração de um ambiente como preferido ou evitado. Finalmente, Sebastião Gobbi, Leonardo Pierrobon Caritá, Márcio Sussumu Hirayama, Antonio Carlos de Quadros Junior, Ruth Ferreira Santos e Lílian Teresa Bucken Gobbi, ao identificar a baixa adesão de idosos institucionalizados à pratica de atividade física, bem como os motivos dessa inatividade, sugerem estratégias para o aumento da eficácia dos programas de atividade física em instituições de longa permanência.

No contexto da Psicologia da Saúde, Tonantzin Ribeiro Gonçalves e Cesar Augusto Piccinini examinam a experiência da maternidade em portadoras de HIV/Aids que receberam o diagnóstico da doença antes de engravidarem ou na ocasião do parto. A ocorrência de depressão em indivíduos cardiopatas, com ou sem diagnóstico de infarto agudo do miocárdio, e em indivíduos sem diagnóstico de cardiopatia é investigada por Conceição Lemos, Carlos A. M. Gottschall, Lucia C. Pellanda e Marisa Muller. Por sua vez, Tatiana Gomez Espinha e Mauro Martins Amatuzzi, ao avaliarem as relações interpessoais vivenciadas por indivíduos hospitalizados, argumentam que é necessário rever os cuidados psicológicos prestados nos hospitais.

$\mathrm{Na}$ área de Psicologia Clínica, Terezinha Feres-Carneiro e Orestes Diniz-Neto apresentam uma revisão histórica das principais abordagens teórico-metodológicas da psicoterapia de casal e, em seguida, ressaltam contribuições recentes do movimento feminista, da perspectiva transcultural e das críticas pós-modernas. Zilda Aparecida Pereira Del Prete e Almir Del Prete, ao defenderem a utilização do Método J na avaliação da confiabilidade e da significância clínica da intervenção psicológica, enfatizam a racional e as questões metodológicas e práticas relacionadas ao uso desse método.

No âmbito da memória, Gustavo Gauer e William Barbosa Gomes apontam que a lembrança de eventos pessoais importantes é mais relacionada aos significados atribuídos a posteriori a esses eventos (julgamentos reflexivos) do que às qualidades fenomenais do próprio ato de lembrar (julgamentos heurísticos). No contexto dos processos perceptuais, Melyssa Kellyane Cavalcanti e Natanael Antonio dos Santos examinam os efeitos da ingestão moderada de álcool sobre a percepção visual de mulheres ou, mais especificamente, sobre a sensibilidade ao contraste. Uma análise conceitual é oferecida por Bruno Angelo Strapasson e Alexandre Dittrich, que discutem duas interpretações, oferecidas por Skinner, para o conceito de "prestar atenção": uma, baseada na noção de controle discriminativo; outra, na de comportamento precorrente.

Jorge Artur Peçanha de Miranda Coelho, Francisco José Batista de Albuquerque, Cíntia Ribeiro Martins, Henrique Barboza D'Albuquerque e Maria Tereza de Souza Neves analisam o papel do pensamento construtivo e da estratégia de coping frente à expectativa de inserção ocupacional e suas conseqüências sobre indicadores de depressão em 
estudantes de ambientes rurais e urbanos. A identificação de evidências de validade fatorial e de consistência interna do Questionário de Metas de Realização para o contexto brasileiro, por sua vez, é o objetivo do estudo de Valdiney V. Gouveia, Pollyane K. da Costa Diniz, Walberto Silva dos Santos, Rildésia S. V. Gouveia e Jane Palmeira Nóbrega Cavalcanti. Finalmente, Luciana Mourão e Jacob A. Laros discutem questões metodológicas referentes à avaliação de programas sociais, com foco no Plano Nacional de Qualificação do Trabalhador (PLANFOR).

Como não poderia deixar de ser, é preciso registrar agradecimentos a todos os que contribuíram para a elaboração dos quatro números do volume 24 desta revista: editores científicos, conselheiros editoriais, consultores ad hoc, técnicos, revisores de línguas, diagramadores e, em especial, aos autores dos trabalhos selecionados, pela demonstração de apreço na escolha de nosso periódico.

Por fim, é necessário manifestar reconhecimento pelo inestimável apoio financeiro prestado pelo CNPq e pela CAPES, instituições cuja contribuição para o desenvolvimento da ciência em nosso país é notória.

Ao reiterar o compromisso de manter esta revista como referência na disseminação e no desenvolvimento da Psicologia no Brasil, desejo que a leitura deste exemplar, dada a excelência dos artigos nele contidos, seja uma atividade enriquecedora.

\section{Josele Abreu-Rodrigues} Editora 